\title{
A scientific bridge in anatomy
}

Anatomy 2007; $1: 3$

Dear Colleagues,

We all know that human anatomy has been and will be a source of fascination in the field of scientific inquiry. So, we all try to contribute to this science by disseminating our findings. It is no doubt that one of the most effective sources of sharing knowledge are the scientific journals.

So, when we started designing the concept of "Anatomy" we already knew that our newborn baby would not be the first journal in the area of clinical and experimental anatomy. Yet, we thought that living in a country with its unique situation of being a bridge between the East and the West would help us to produce a journal with a different flavor. With this motto in front of us, we decided that our journal would be open to original papers providing a link between gross anatomy and areas related with clinical anatomy, such as, experimental and functional anatomy, neuroanatomy, comparative anatomy, modern imaging techniques, molecular biology, cell biology and embryology and morphological studies of veterinary discipline.

In addition, bearing in mind that human anatomy is one of the fundamentals of medical education, manuscripts dealing with all forms of anatomical teaching will be considered for publication as well.

"Anatomy", International Journal of Experimental and Clinical Anatomy will be the official publication of Turkish Society of Anatomy and Clinical Anatomy, TSACA. The language of the journal will be English and it will be printed once a year. The journal will contain both electronic and printed versions. In the future, we are planning to increase the number of issues published.
Before concluding, we would especially like to thank our editors and scientific board members and all others who have given their unconditional support for the publishing of Volume 1.

We also would like to underline that the presence of distinguished scientists from reputable universities all around the world strengthens our confidence that "Anatomy" will be able to reach the highest level in the world of scientific journals. So I extend my deepest and most sincere thanks for their acceptance to be a member of our Scientific Advisory Board.

We also do not forget the authors who have contributed with their works to the birth of "Anatomy", so our thanks go to them as well.

The first volume consists of the abstracts of 11th National Congress of Anatomy with International Participation. Starting from the second volume, "Anatomy" will be back to stage with original manuscripts.

With your support behind us we will never give up seeking the excellence. Looking forward to meeting you in our next issue.

"Per scientiam ad salutem aegroti"*

H. Hamdi Çelik

Editor-in-Chief

President of TSACA

*To heal the sick through knowledge 